\title{
Welfare and Productivity Impact of Adoption of Biofortified Cassava by Smallholder Farmers in Nigeria
}

ADETOMIWA KOLAPO ( $\nabla$ kolapoadetomiwa@gmail.com )

Obafemi Awolowo University Faculty of Agriculture https://orcid.org/0000-0002-0808-1293

Adeyera James Kolapo

University of Ilorin Faculty of Agriculture

Research

Keywords: Biofortified cassava, Adoption, Productivity, Smallholders, Welfare, Nigeria

Posted Date: July 27th, 2020

DOI: https://doi.org/10.21203/rs.3.rs-47869/v1

License: (c) (1) This work is licensed under a Creative Commons Attribution 4.0 International License.

Read Full License

Version of Record: A version of this preprint was published at Cogent Food \& Agriculture on January 1st, 2021. See the published version at https://doi.org/10.1080/23311932.2021.1886662. 


\title{
WELFARE AND PRODUCTIVITY IMPACT OF ADOPTION OF BIOFORTIFIED CASSAVA BY SMALLHOLDER FARMERS IN NIGERIA
}

${ }^{1}$ KOLAPO ADETOMIWA* and ${ }^{2}$ KOLAPO ADEYERA JAMES

\author{
${ }^{1}$ Department of Agricultural Economics, Faculty of Agriculture, Obafemi Awolowo University, \\ Ile-Ife, Nigeria. \\ ${ }^{2}$ Department of Agricultural Economics and Farm Management, Faculty of Agriculture, \\ University of Ilorin, Kwara State, Nigeria. \\ *Correspondence Email: kolapoadetomiwa@ gmail.com
}

\begin{abstract}
In the bid to improve the productivity, welfare and vitamin-A intake of SSA farmers, Biofortified cassava was bred. This study examined the welfare and productivity impact of adoption of biofortified cassava using a household-level data from smallholder farmers in Nigeria. We used instrumental variable regression to control for endogeneity. The results obtained from the study showed that adoption of biofortified cassava increased farm yield, farmers income and welfare outcomes of adopters of biofortified cassava. In addition, the distributional impact of the adoption of the biofortified cassava showed heterogeneity effect based on gender and farm size. Overall, the study suggests that since the largest proportion of the cassava farmers in Nigeria are mostly smallholder farmers, distribution and circulation of biofortified cassava stem cuttings should be targeted towards the smallholder farmers so as to improve their productivity, income and welfare and subsequently reduce their poverty status and ensure food security.
\end{abstract}

Keywords- Biofortified cassava, Adoption, Productivity, Smallholders, Welfare, Nigeria.

\section{INTRODUCTION}

Cassava is an important staple food in Nigeria. Cassava is a starchy crop which contributes to the staples of millions in sub-Saharan Africa (SSA). According to Otekunrin and Sawicka (2019), about 177,948 million tonnes of cassava were produced in Africa. Nigeria is regarded as the world's largest producer of cassava with a total of about 20.4 percent of the world export in year 2017 (Otekunrin and Sawicka, 2019). Cassava is an essential component of the diet of about 70 million Nigerians (FAO, 2013). Nigeria, being the largest producer of cassava in the world is producing an average annual estimate of 45 million metric tons which had been translated into a major global market share of about 19 percent (Phillips et al., 2004).

However, the predominant cassava varieties in Nigeria were found to be deficient of the necessary nutrients as its been regarded as starchy food. Nutrients such as Vitamin-A was found lacking in the normal white cassava and this has greatly contributed to the issue of malnutrition in Nigeria. Vitamin A deficiency has been posing a threat to human survival for a very long time 
and the world has put a lot of measures in place to combat this threat. According to Rice et al. (2004), several international organizations in the world such as United States Agency for International Development (USAID), United Nations Children Education Fund (UNICEF), World Health Organization (WHO) among others have been tirelessly working on how to upsurge this menace for a long period of time till present. Many special intervention programs have been implemented in developing countries; Nigeria inclusive. One of such intervention programs is the more recently biofortification - a term used to describe a breeding strategy that aims to increase the micronutrient content of staple food crops (Nestel et al., 2006). Through biofortification, staple food crops that are enriched with beta-carotene, a precursor of vitamin A in the body, have been bred. Bio-fortified cassava is one of these crops. The production of biofortified vitamin-A cassava started in 2011 with the intervention of the International Center for Tropical Agriculture (CIAT) and the International Institute of Tropical Agriculture (IITA) which were funded by Harvest Plus program. Five years after the intervention program, statistics revealed that over 1million of Nigerian farming households grows yellow cassava varieties that contains substantial quantities of vitamin-A even after processing. In Nigeria diets today, yellow bio-fortified cassava represents additional source of vitamin A (Saltzman et al., 2014). The biofortified cassava was produced with the aim of improving the nutrients of the consumers, increase the productivity and welfare of the farmers.

Biofortified cassava promised a greater yield and better income to farmers. To increase productivity, improved technology such as biofortified cassava must be adopted in the production process and the rate of adoption of a new technology is subject to its profitability, degree of risk associated with it, capital requirements, agricultural policies and socioeconomic characteristics of farmers (Afolami et al., 2015). The adoption of innovation is the last step in a decision process to make full use of an innovation having considered that such will impact positively on the likelihood of the adopter (Afolami et al., 2015). The significance of this study lies with the fact that increasing the productivity, income and welfare of the farmer through adoption of agricultural technology such as biofortified cassava has been a major cause of concern for the underdeveloped and developing countries including Nigeria for long period of time. According to Afolami et al., (2015) intensification of better agricultural production system is one of the ways of increasing the welfare of farmers and this can be achieved if farmers take advantage of improved crop varieties such as biofortified cassava. 
Regardless, there is little empirical evidence on the impact of adoption of biofortified cassava to inform on-going debate on how effectively the adoption of biofortified cassava had increased productivity and welfare of poor smallholder farmers in Nigeria. In this study we empirically ascertained whether the adoption of biofortified cassava in Nigeria increases productivity and improves welfare outcomes. Biofortified cassava yield and income from biofortified cassava production are used as a proxy for productivity outcomes in this study, while per-capita food, total, and non-food expenditure were used as indicators for welfare outcomes. We focus on productivity and welfare outcomes as they are the most important indicators in measuring the impact of adoption of improved technologies.

This study contributes to the literature on biofortification in the following ways: First, by focusing on one of the country that first accepted biofortification in SSA, it investigates the enduring question of whether and to what extent adoption of biofortified cassava impacts productivity and welfare outcomes. To date, there is not a single study that evaluated the impact of adoption of biofortified cassava on productivity and welfare of smallholder farmers in Nigeria. In addition, this study is the first to evaluate the impact of adoption of biofortified cassava on welfare of smallholder farmers in Nigeria. Second, in an attempt to provide beyond average treatment effects, we examine the distributional impacts of the adoption of biofortified cassava focusing on two sources of heterogeneity: gender and farm size. In principle, the adoption of biofortified cassava, ceteris paribus, only improve the income of smallholder farmers. However, leakages and imperfect targeting may affect the access to biofortified cassava stem away from the intended smallholder farmers since they formed the majority of farmers in Nigeria. Under such circumstances, the adoption of biofortified cassava become beneficial on average by improving the productivity of commercial farmers albeit ineffective in addressing the needs of smallholder farmers. This study, therefore addresses this issue by estimating the overall average impact of the adoption of biofortified cassava as well as its distributional impacts. In estimating the overall average and distributional impacts of the adoption of biofortified cassava, we control for the potential endogeneity of adopting the biofortified cassava using Instrumental Variable (IV) regression approach. We also examined the robustness of estimated impacts by constructing alternative measures of adoption of biofortified cassava. 


\section{Data source and Econometric techniques}

The study was carried out in Nigeria. This study uses a household survey cross sectional data collected by the researcher and well-trained data enumerators in 2019. A multi-stage sampling procedure was used to select sampled areas from each Local Government Areas and households from each selected sampled areas. A list of biofortified cassava farmers who purchased the biofortified stem was accessed from ADPs. Following the NBS recommendation for a nationally representative data collection (NBS, 2010), 10\% of the LGAs in each of the selected States and $5 \%$ of the total sampled areas per LGA were randomly selected. Finally, from the households in each of the selected sampled areas, eight farming households were randomly selected which resulted in a sample size of 3,497 households. The data were collected using well-structured questionnaire which was pre-tested before final enumeration. The survey questionnaire was designed to gather detailed information on socio-economic characteristics of households, input use and allocation, expenditure on food and non-food items, awareness of the biofortified cassava varieties, yield of biofortified cassava and adoption of biofortified cassava. In addition, extensive village-level data were collected on the incidence of shocks, prices of key inputs, among others. In terms of adoption of biofortified cassava, relevant data were collected on the level of awareness about the biofortified cassava as well as on farmers' decision to adopt the biofortified cassava. The data for this study were collected electronically using the "ODK Collect” App.

\section{Econometric Techniques}

Establishing the impacts of adoption of improved agricultural technologies on various outcome is not an easy task. The improved technologies such as biofortified cassava stems are rarely distributed randomly across communities and among farmers. As such, identifying the causal impacts of adoption of an improved technology requires controlling for selection bias/endogeneity stemming from observable and unobservable factors. In non-experimental data, common approaches for identifying causal impacts include different matching techniques, fixed effects, and instrumental variable (IV) regression. In this study, we employed an inverse probability-weighted adjusted regression (IPWRA) and IV regression approach due to the crosssectional nature of data collected. We make use of the IPWRA estimator in order to achieve some robustness to misspecification of the parametric models (Imbens \& Wooldridge, 2009; 
Robins \& Rotnitzky, 1995; Wooldridge, 2010) instead of propensity score matching (PSM) where the estimates produce biased results in the presence of misspecification in the propensity score model (Robins, Sued, LeiGomez, \& Rotnitzky, 2007; Wooldridge, 2007; Wooldridge, 2010).

IPWRA model estimates the outcome and treatment models as follows: Suppose that the outcome model is represented by a linear regression function of the form $Y i=\alpha i+\theta i x i+\varepsilon i$ for $\{0$ 1) where $\mathrm{Y}_{\mathrm{i}}$ is the outcome variable of interest; $x i$ a set of controls; $\alpha$ and $\theta$ are the parameter to be estimated; $\varepsilon$ is the error term. Furthermore, we employ linear regression to estimate $(\alpha 0, \theta 0)$ and $(\alpha 1, \theta 1)$ using inverse probability-weighted least squares as follows:

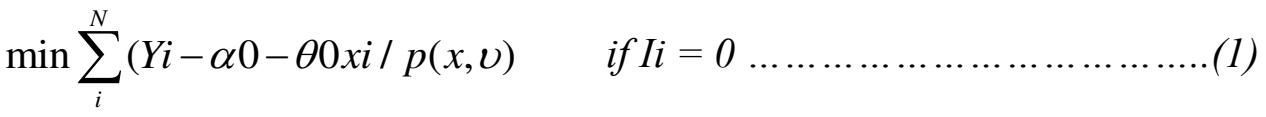

$$
\begin{aligned}
& \min \sum_{i}^{N}(Y i-\alpha 1-\theta 1 x i / p(x, v) \quad \text { if } I i=1
\end{aligned}
$$

The average treatment effect (ATT) is then computed as the difference between Eqns. (1) and (2).

$$
\left.A T T=\frac{1}{N} \sum_{i}^{N}[\alpha 1-\alpha 0)-(\theta 1-\theta 0) x i\right]
$$

Where $(\alpha 1)$ are estimated inverse probability-weighted parameters for households that adopted the biofortified cassava while $(\alpha 0)$ are estimated inverse probability-weighted parameters for non-adopters. Finally, $\mathrm{N}$ represents the total number of biofortified cassava adopters. $I i$ is an indicator which takes a value of 1 if the farmer adopts the biofortified cassava and 0 otherwise.

However, casual identification requires controlling for both observable and unobservable factors that influence adoption of biofortified cassava and productivity and welfare outcomes. Hence, estimates of Eq. (3) may yield biased estimates due to biases stemming from unobservable factors. Therefore, we employed an IV regression approach to control for the potential endogeneity of adoption of biofortified cassava. There are several reasons for adoption of biofortified cassava to be endogenous. First, households that are either more or less productive than the average smallholder may choose to adopt the biofortified cassava. Hence, it is likely that 
adoption of biofortified cassava is correlated with poverty status, household income, or underlying features that influence these outcome variables (Chibwana, Fisher, \& Shively, 2012; Ricker-Gilbert, Mason, Darko, \& Tembo, 2013; Ricker-Gilbert et al., 2011; Shively, Chibwana, Fisher, Jumbe, \& Masters, 2012). Second, there is a possibility that farmers who adopted the biofortified cassava share common intrinsic characteristics, such as poor/better farming skills and management abilities, which are likely to be related to poverty status and household income. As a result, we employed an IV regression approach. Following the literature, we used the access to land resources as potential instrument for the adoption of biofortified cassava. The land ownership status a farmer has is a measure of access to land resources that could influence farmer's adoption of biofortified cassava (Afolame et al., 2015). We assume that this variable has no direct effect on productivity and welfare outcomes except through its effect on farmers' decisions to adopt biofortified cassava.

Furthermore, the decision to adopt and intensity of adoption of biofortified cassava depends on a number of socioeconomic and institutional factors. Therefore, the decision to adopt and intensity of adoption of biofortified cassava was captured using Cragg's double hurdle regression.

\section{The Cragg's model two-step estimation procedure}

The Cragg's model was chosen for this study because it relaxes the restrictive assumption of the Tobit model that the factors influencing the discrete decision (adoption decision) and the continuous decision (intensity of adoption) as well as their effects are the same. Hence, in the Cragg's model, the coefficients of the dependent variables of the first and second hurdle are different. The first step analyses the factors influencing the decision of farmers to adopt biofortified cassava varieties, while the second step deals with the intensity of adoption of biofortified cassava varieties.

Step 1: Probit model for the discrete adoption decision

For the Probit model, we assume that the decision of the ' $i$ 'th farmer to adopt a technology or not depends on an unobservable utility index $\mathrm{Y}_{\mathrm{i}}{ }^{*}$, that is determined by the explanatory variables, and that the higher the value of this utility index the higher the probability that the farmer will adopt the technology. The adoption probability (dependent variable) $Y_{\mathrm{i}}$ is limited between the values of 1 and 0 . 


$$
Y_{i}=\left\{\begin{array}{c}
Y_{i}^{*} \text { if } Y_{i}^{*}>0 \\
0 \text { if } Y_{i}^{*} \leq 0
\end{array}\right\}
$$

The Probit model is expressed as:

$$
\operatorname{Prob}\left(\mathrm{Y}^{*}>0\right)=\mathrm{F}\left(\mathrm{X}^{\prime} \beta\right)=\Phi\left(\mathrm{X}^{\prime} \beta\right)=\int_{-\infty}^{\mathrm{X} / \beta} \emptyset(\mathrm{Z}) \mathrm{dZ} \ldots \ldots \ldots \ldots .(5)
$$

Where; $F\left(X^{\prime} \beta\right)=$ cumulative degree of freedom of the standard normal distribution.

$\mathrm{Y}_{\mathrm{i}}^{*}=\mathrm{X}^{\prime} \beta+\varepsilon i$

Where $Y_{i}^{*}$ is the independent variables ( $1=$ adoption, $0=$ otherwise) and $X^{\prime} \beta$ are the set of dependent variables, $\varepsilon i_{\text {] }}$ is the error term.

Step 2: Model for the continuous decision (intensity of adoption using uncensored observations)

$$
\mathrm{E}\left(\mathrm{Y} \mid \mathrm{Y}^{*}>0\right)=\mathrm{X}^{\prime} \gamma+\sigma \lambda\left(\frac{\mathrm{X}^{\prime} \gamma}{\sigma}\right) \ldots
$$

Here the Cragg's model makes use of uncensored observations i.e. the observations with zero adoption level were not cut out of the observation, thus giving a better representation of the population.

$$
\mathrm{Y}_{\mathrm{i}}^{*}{ }^{*} \mathrm{X}^{\prime} \gamma+\varepsilon i
$$

$\mathrm{Y}_{\mathrm{i}}^{*}$ is the dependent variable (intensity of adoption) and $\mathrm{X}^{\prime} \gamma$ are set of independent variables. $\varepsilon i_{\text {[] }}$ is the error term

\section{Outcome indicators}

The outcome indicators are related to productivity and welfare. Our first productivity outcomerelated indicator is biofortified cassava yield. Our second productivity-related indicator is measured by income from biofortified cassava production. Looking into the distribution of income from biofortified cassava production, income received from cassava sales is higher for the adopters of biofortified cassava (Table 2). However, these differences in biofortified cassava yield and income cannot simply be attributed to the adoption of biofortified cassava by looking at the mean differences between adopters and non-adopters. In particular, these mean differences are only indicative of correlations and cannot be used to make causal inferences regarding the impacts of the adoption of biofortified cassava on yields and income without controlling for other confounding factors. Our welfare-related indicators include food expenditure, non-food expenditure, and total expenditure, all measured on per-capita basis. In addition to expenditure indicators, we also used headcount poverty ratio as an additional welfare indicator. Total 
expenditure is calculated by summing food and non-food expenditure values. A household's food consumption expenditure is comprised of monetary expenditures on purchased food and the imputed values of consumption from own harvest. Looking into the distribution of consumption expenditures, the average per capita total consumption expenditure is about 124,119 per year (Table 2). Like productivity indicators, we found significant differences in per capita food, nonfood, and total consumption expenditures for adopters and non-adopters of biofortified cassava (Table 2). However, as mentioned above, these differences between adopters and non-adopters cannot be entirely attributed to production of biofortified cassava only. Our final welfare related outcome indicator measures the proportion of households below the poverty line, commonly referred as the headcount ratio. Following Foster, Greer, and Thorbecke (1984), per-capita total expenditure is used to determine households' poverty status. Formally, headcount ratio $\left(\mathrm{P}_{0}\right)$ is calculated as:

$$
P \alpha=\frac{1}{n} \sum_{i=1}^{q}\left(\frac{z-y i}{z}\right) \alpha
$$

Where $\mathrm{n}$ is the total number of the people in the group, $\mathrm{q}$ is the number of poor, $\mathrm{Z}$ is the poverty line, $\mathrm{Yi}$ is the value of the per capital consumption expenditure of the ith person and $\alpha$ is the poverty aversion parameter. The classification of the poverty status was as follows; (i) Non-poor: These are respondents whose per capital consumption expenditure is above the poverty line. That is, $\mathrm{P}>2 / 3$ of the mean per capita consumption expenditure per year. (ii) Poor: These are respondents whose per capita consumption expenditure is below the poverty line. That is, $\mathrm{P}<2 / 3$ of the mean per capita consumption expenditure per year.

\section{EMPIRICAL RESULTS AND DISCUSSION}

\section{Descriptive statistics}

In the household survey, detailed information were collected regarding the awareness and adoption of biofortified cassava. More specifically, households were asked if they were aware of biofortified cassava varieties. Second, those who responded in the affirmative were asked if they had adopted the biofortified cassava. According to the survey, about $71.3 \%$ of the households were aware of the biofortified cassava and only $52.6 \%$ of them adopted the biofortified cassava. Since our main objective is to evaluate the overall impact of adoption of biofortified cassava on productivity and welfare outcomes, we used adoption status of the farmers as our main treatment variable. In particular, adoption status is measured by a dummy variable which takes a value of 
one if the farmer adopted the biofortified cassava and zero otherwise. In the robustness section, access to biofortified cassava stem was used as our treatment variables. Table 1 presents the descriptive statistics of the key variables of interest based on the adoption status of households. We included household characteristics such as age, household size, education, membership in different social groups, risk-aversion, drought shocks as well as farm size. In addition, we have included access to extension services as these variable affect awareness and adoption decision of biofortified cassava. We assume that the above key household characteristics affect farmers' ability to adopt biofortified cassava. For instance, we hypothesize that the education level of the farmer affects the likelihood of adoption of biofortified cassava positively. However, for most of our controls, the direction of expected impacts cannot be determined a priori. The variable riskaversion is measured by farmer's willingness to try new agricultural technology such as biofortified cassava. In particular, data were collected on how willing the farmers are to take risks related to new improved biofortified cassava varieties. We consider farmers as risk-averse if they are unwilling to ever try new improved varieties. However, given the proxy nature of our measurement, its effect should be interpreted with caution. In addition to household characteristics, we also included state dummies to control for state-level fixed effects. Finally, the land ownership status serves as an instrument for the adoption of biofortified cassava. Table 1 further presents the difference in means between adopters and non-adopters of biofortified cassava. From Table 1, adopters of biofortified cassava were found to be literate although there is a considerable proportion of non-adopters that were literate also. It was found that there was a significant mean difference in the educational level of the adopters and non-adopters which shows that the adopters were more educated than the non-adopters. This might have influenced their decision in adopting the technology. Table 1 shows that there was a significant mean difference in access to credit by the adopters (71 percent) and non-adopters (58 percent). The adopters of biofortified cassava were found to be majorly male (79 percent) with the nonadopters being 58 percent. About 26 percent of the adopters were found to have experienced drought shock which might be attributed to climate change while 18 percent of the non-adopters had experienced drought shock in the time past. Extension services was very instrumental in the adoption of agricultural technologies as 84 percent of the adopters had access to extension services while 47 percent of the non-adopters had access to extension service in the past. This might have contributed to the decision to adopt biofortified cassava among the adopters. 
Regarding the membership to credit and saving groups, 88 percent of the adopters were members while 52 percent of the non-adopters were member. We found a significant mean difference in access to climate condition between the adopters and non-adopters of biofortified cassava as many of the adopters of biofortified cassava had access to climatic information. On average, about 96 percent of the adopters were willing to try new things while 51 percent of the nonadopters were willing. About 82 percent of the adopters of biofortified cassava had access to land resources while 67 percent of the non-adopters had access to land. From Table 2, a mean significant difference was found in the yield of biofortified cassava among the adopters $(4,013 \mathrm{~kg} / \mathrm{ha})$ and non-adopters $(3,418 \mathrm{~kg} / \mathrm{ha})$. This shows that on average, adopters of biofortified cassava has a mean yield more than the non-adopters. We also found that there is a significant mean difference in the income of the adopters $(\$ 153,582)$ and non-adopters $(N 98,158)$. On average, a mean significant difference was found between the total, food and non-food expenditure of the adopters and non-adopters of biofortified cassava. 
Table 1: Descriptive statistics by adoption status of biofortified cassava

\begin{tabular}{|c|c|c|c|c|}
\hline & $\begin{array}{c}\text { Full sample } \\
(\mathbf{N}=\mathbf{3 , 3 2 1})\end{array}$ & $\begin{array}{l}\text { Adopters } \\
(\mathbf{N}=1,397)\end{array}$ & $\begin{array}{l}\text { Non-adopters } \\
(\mathbf{N}=\mathbf{1 , 9 2 4 )}\end{array}$ & Mean diff \\
\hline Education & 0.72 & 0.87 & 0.73 & $0.14 * * *$ \\
\hline Household size & 7.68 & 8.3 & 7.9 & $0.4 * * *$ \\
\hline Marital status $(1=$ married, $0=$ otherwise $)$ & 0.91 & 0.94 & 0.92 & 0.02 \\
\hline Years of Experience & 16.5 & 17.3 & 16.9 & $0.4 * * *$ \\
\hline Age of the household head & 48.1 & 49.74 & 47.28 & $2.46 * * *$ \\
\hline Access to credit ( $1=$ yes, $0=$ otherwise $)$ & 0.62 & 0.71 & 0.58 & $0.13 * *$ \\
\hline Gender of the household head ( $1=$ male, $0=$ otherwise $)$ & 0.67 & 0.79 & 0.58 & $0.21 * * *$ \\
\hline Farm size (ha) & 4.12 & 4.82 & 4.46 & $0.36 * *$ \\
\hline Access to off-farm income ( $1=$ has access, $0=$ otherwise $)$ & 0.42 & 0.49 & 0.43 & 0.06 \\
\hline Drought shock ( $1=$ experience drought, $0=$ otherwise $)$ & 0.23 & 0.26 & 0.18 & $0.08 * *$ \\
\hline Membership to cooperatives ( $1=$ yes, $0=$ otherwise $)$ & 0.38 & 0.42 & 0.35 & 0.07 \\
\hline Membership to credit and saving group ( $1=$ yes, $0=$ otherwise $)$ & 0.81 & 0.88 & 0.52 & $0.36 * * *$ \\
\hline Access to extension services ( $1=$ has access, $0=$ otherwise $)$ & 0.72 & 0.84 & 0.47 & $0.37 * * *$ \\
\hline Access to climate information ( $1=y e s, 0=$ otherwise $)$ & 0.61 & 0.76 & 0.35 & $0.41 * * *$ \\
\hline Risk aversion ( $1=$ willing to try new things, $0=$ otherwise $)$ & 0.73 & 0.96 & 0.51 & $0.45 * * *$ \\
\hline Access to land resources ( $1=$ has access, $0=$ otherwise $)$ & 0.64 & 0.82 & 0.67 & $0.15 * * *$ \\
\hline Access to training $(1=$ yes, $0=$ training $)$ & 0.67 & 0.76 & 0.44 & $0.32 * * *$ \\
\hline
\end{tabular}

Final sample includes 3,321 farmers due to missing values for inputs, yield, expenditure and other controls. 
Table 2: Descriptive statistics by adoption status of biofortified cassava for yield, income and expenditure

\begin{tabular}{lcccc}
\hline & $\begin{array}{c}\text { Full sample } \\
(\mathbf{N = 3 , 3 2 1})\end{array}$ & $\begin{array}{c}\text { Adopters } \\
(\mathbf{N = 1 , 3 9 7 )}\end{array}$ & $\begin{array}{c}\text { Non-adopters } \\
(\mathbf{N = 1 , 9 2 4 )}\end{array}$ & Mean diff \\
\hline Biofortified cassava yield (kg/ha) & 3,743 & 4,013 & 3,418 & $595 * * *$ \\
Income from biofortified cassava production ( $)$ & 118,482 & 153,582 & 98,158 & $55,424 * * *$ \\
Per capita total expenditure ( $)$ & 124,119 & 167,582 & 131,459 & $36123 * * *$ \\
Per capita food expenditure ( $)$ & 67,351 & 87,232 & 68,192 & $19,040 * * *$ \\
Per capita non-food expenditure (N) & 56,768 & 80,350 & 63,267 & $17,083 * * *$ \\
\hline
\end{tabular}

Final sample includes 3,321 farmers due to missing values for inputs, yield, expenditure and other controls. 
TABLE 3: Impacts of adoption of biofortified cassava on outcomes of interest using IPWRA

estimation

Treatment variable $=\mathbf{1}$ if farmer adopted biofortified cassava IPWRA

Biofortified cassava yield

$0.47 * *$

(0.198)

Income from biofortified cassava production

$0.54 * * *$

(0.186)

Total expenditure

$0.45 * *$

(0.199)

Food expenditure

$0.51 * * *$

(0.150)

Non-food expenditure

$0.42 * * *$

(0.102)

Poverty head count ratio

$-0.19 * * *$

(0.069)

$\mathrm{N}$

3,321

Robust standard error in bracket, ***,** Significant at $1 \%$ and $5 \%$ respectively.

Matching impact estimator on outcome indicators 
The result of the IPWRA estimation on various outcome indicators including biofortified cassava yield; income from biofortified cassava production; per-capita total expenditure; per-capita food expenditure and poverty headcount ratio were presented in Table 3. We find a positive and statistically significant impact of adoption of biofortified cassava on all productivity and welfare outcome indicators. The results presented in Table 3 shows that adoption of biofortified cassava increased yields and income by $47 \%$ and $54 \%$ respectively. Regarding welfare outcomes, we found positive and statistically significant impacts on consumption and a negative and statistically significant impact on poverty headcount ratio. In essence, the probability of being poor declined by $19 \%$ due to the adoption of biofortified cassava. Although, these results need to be interpreted with caution and in fact they may be biased since we did not control for unobserved heterogeneity.

Determinants of adoption and intensity of adoption of biofortified cassava (probit and truncated regression) 
We used the probit model (first hurdle) to examine the determinants of adoption of biofortified cassava while truncated regression (second hurdle) was used to examine the intensity of adoption of biofortified cassava as stated in the methodology section. Results of the probit model indicates that the included IV (access to land resources) affects the probability of adopting biofortified cassava (Table 4). This implies that the selection bias has been remedied by the IV. Examining the determinants of adoption of biofortified cassava, we found that farmer characteristics such as education, years of experience, gender of the household head, farm size membership to cooperatives, membership to credit and savings group, access to extension services, risk aversion, access to land resources and access to training all influenced positively, the probability of adopting the biofortified cassava. Marginal effects were computed in order to ascertain the percentage change that might contributes to the probability of adoption of biofortified cassava. This result is consistent with the findings of Oparinde et al. (2016). In addition, the likelihood estimates of the probit regression indicated that the Chi-square statistics of 43.29185 was highly significant $(\mathrm{p}<0.0001)$ which suggested that the model has a strong explanatory power. Regarding the intensity of adoption (truncated regression) of biofortified cassava presented in Table 5, we found that farmers characteristics such as education, household size, marital status,

years of experience, farm size, access to off-farm income, drought shock, membership to cooperatives, membership to credit and savings group, access to extension services, access to climate information, access to land resources and access to training positively influenced the intensity of adoption of biofortified cassava among the farmers.

TABLE 4: Parameter estimates of the probit model Variable Coeff. Stand. Err. t-value Marginal effect 


\begin{tabular}{|c|c|c|c|c|}
\hline Education & $0.297 * * *$ & 0.079 & 3.75 & 0.016 \\
\hline Household size & 0.010 & 0.006 & 1.45 & 0.024 \\
\hline Marital status & 0.003 & 0.006 & 0.51 & 0.043 \\
\hline Years of Experience & $0.217 * * *$ & 0.081 & 2.68 & 0.039 \\
\hline Age of the household head & 0.050 & 0.120 & 0.42 & 0.021 \\
\hline Access to credit & $1.70 \mathrm{E}-07$ & $2.55 \mathrm{E}-07$ & 0.67 & 0.037 \\
\hline Gender of the household head & $0.333 * * *$ & 0.11 & 2.96 & 0.063 \\
\hline Farm size & $0.023 *$ & 0.012 & 1.87 & 0.046 \\
\hline Access to off-farm income & 0.209 & 0.156 & 1.34 & 0.066 \\
\hline Drought shock & 0.051 & 0.158 & 0.32 & 1.585 \\
\hline Membership to cooperatives & $0.203 * *$ & 0.096 & 2.11 & 0.051 \\
\hline Membership to credit and saving group & $1.893 * * *$ & 0.715 & 2.65 & 0.040 \\
\hline Access to extension services & $0.129 * * *$ & 0.020 & 6.21 & 0.024 \\
\hline Access to climate information & 0.050 & 0.053 & 0.94 & 0.762 \\
\hline Risk aversion & $0.053^{* *}$ & 0.022 & 2.34 & 0.748 \\
\hline Access to land resources & $0.756^{* *}$ & 0.367 & 2.06 & 0.046 \\
\hline Access to training & $0.233 * * *$ & 0.051 & 4.51 & 0.098 \\
\hline State fixed effects & Yes & & & \\
\hline Number of observations & 3,321 & & & \\
\hline Prob > chi 2 & 0.0001 & & & \\
\hline Log likelihood & 43.29185 & & & \\
\hline
\end{tabular}

TABLE 5: Parameter estimates of the truncated regression model \begin{tabular}{llll}
\hline Variable & Coeff. & Stand. Err. & t-value
\end{tabular} 


\begin{tabular}{llll}
\hline Education & $0.072^{*}$ & 0.040 & 1.78 \\
Household size & $2.259^{* *}$ & 0.943 & 2.4 \\
Marital status & $2.47 \mathrm{E}-06^{*}$ & $1.40 \mathrm{E}-06$ & 1.77 \\
Years of Experience & $1.585^{*}$ & 0.918 & 1.73 \\
Age of the household head & 0.063 & 0.046 & 1.37 \\
Access to credit & 1.080 & 0.748 & 1.44 \\
Gender of the household head & 0.323 & 0.558 & 0.58 \\
Farm size & $2.833^{* * *}$ & 0.945 & 3.00 \\
Access to off-farm income & $6.601^{* * *}$ & 2.45 & 2.69 \\
Drought shock & $5.780^{* *}$ & 2.754 & 2.1 \\
Membership to cooperatives & $9.796^{* *}$ & 4.365 & 2.24 \\
Membership to credit and saving group & $0.130^{* * *}$ & 0.050 & 2.56 \\
Access to extension services & $1.744^{*}$ & 1.004 & 1.74 \\
Access to climate information & $3.65 \mathrm{E}-06^{*}$ & $1.92 \mathrm{E}-06$ & 1.90 \\
Risk aversion & 0.703 & 0.68 & 1.02 \\
Access to land resources & $2.705^{* *}$ & 1.258 & 2.15 \\
Access to training & $0.074^{* *}$ & 0.038 & 1.95 \\
State fixed effects & Yes & & \\
Constant & $1.893^{* * *}$ & 0.715 & 2.65 \\
Sigma & $0.129^{* * *}$ & 0.020 & 6.21 \\
\hline
\end{tabular}

$* * *=$ significant at $1 \%, * *=$ significant at $5 \%, *=$ significant at $10 \%$. 


\section{Impact of adoption of biofortified cassava on farm yields and income}

The result of the impact of adoption of biofortified cassava on the yields and income of farmers is presented in Table 6 and 7 respectively. The parameter estimates of "No control" present a parsimonious specification for biofortified cassava yield and income that includes only the treatment variable along with state-level fixed effects as indicated in Table 6 and 7 respectively. The parameter estimates of "With control", present results where standard controls for biofortified cassava yield and income are included. The parameter estimates of "With IV" present the results of the IV specification where the adoption of biofortified cassava is treated as endogenous. Furthermore, we specify a log-linear functional form for biofortified cassava yield and income from biofortified cassava production is estimated at levels. From Table 6, the results obtained shows that adoption of biofortified cassava has a positive and statistically significant impacts on farmers yields and income. Examining the parsimonious model specification for yield, it was found that the impact of adoption of biofortified cassava is similar considering the direction and magnitude of the estimated impacts. In particular, farmers who adopted biofortified cassava increased their farm yields by $31.1 \%$ when only state-level fixed effects were controlled, $29.7 \%$ when standard controls with state-level fixed effects is included and by $28.5 \%$ when potential endogeneity of adoption of biofortified cassava was controlled. In addition, the estimated results presented in Table 7 suggest an increase in income of famers by 2.16 to 22.21. It should be noted that the values for biofortified cassava income are expressed in $\$ 12,500$. The impact size 2.16 implies that adoption of biofortified cassava increases income of the farmers from the production of biofortified cassava by $\$ 27,000$. The results presented in Table 6 show that farm yield has increased by $28.5 \%$ due to adoption of biofortified cassava varieties. Similarly, farmers (adopters) income has increased by 22,812 . These results obtained implies that the adoption of biofortified cassava has enabled small holder farmers to improve their productivity and income. Furthermore, interaction terms to test if adoption of biofortified cassava has heterogeneous impacts was included in Table 6 and 7. We introduced an interaction term between adoption of biofortified cassava and the gender of the household head as well as between adoption of biofortified cassava and farm size. A dummy variable was created which was referred to as "land category" and this takes on a value of 1 if a household owns less than 1 ha of farmland and 0 otherwise. The result shows that the interaction term between adoption of biofortified cassava and the gender of the household head is significant for both farmers yield 
and income. This result implies that adoption of biofortified cassava benefits the male-headed households more than the female-headed households because more of the male-headed households adopted the biofortified cassava varieties. Similarly, the interaction term between adoption of biofortified cassava and land category is also significant.

TABLE 6: Impact of Adoption of Biofortified Cassava on Farmers Yield

\begin{tabular}{|c|c|c|c|}
\hline & No control & With control & With IV \\
\hline Biofortified cassava & $\begin{array}{l}0.311 * * * \\
(0.119)\end{array}$ & $\begin{array}{l}0.297 * * * \\
(0.100)\end{array}$ & $\begin{array}{l}0.285 * * * \\
(0.077)\end{array}$ \\
\hline Gender & & $\begin{array}{l}0.084 * * * \\
(0.031)\end{array}$ & $\begin{array}{c}1.583 * * * \\
(0.584)\end{array}$ \\
\hline Land category & & $\begin{array}{l}0.060 * * \\
(0.037)\end{array}$ & $\begin{array}{l}0.030 * * \\
(0.021)\end{array}$ \\
\hline Adopters* Gender & & $\begin{array}{l}-0.052 * * * \\
(0.405)\end{array}$ & $\begin{array}{l}0.151 * * \\
(0.451)\end{array}$ \\
\hline Adopters* Land category & & $\begin{array}{c}0.651^{*} \\
(0.420)\end{array}$ & $\begin{array}{l}0.534 * * \\
(0.513)\end{array}$ \\
\hline Education & & $\begin{array}{l}-0.534 \\
(0.513)\end{array}$ & $\begin{array}{l}-0.004 \\
(0.034)\end{array}$ \\
\hline Household size & & $\begin{array}{l}0.024 \\
(0.405)\end{array}$ & $\begin{array}{c}-0.045 \\
(0.424)\end{array}$ \\
\hline Marital status & & $\begin{array}{l}0.966^{* *} \\
(0.491)\end{array}$ & $\begin{array}{l}-0.700 \\
(1.135)\end{array}$ \\
\hline Years of Experience & & $\begin{array}{l}-0.066 * * \\
(0.027)\end{array}$ & $\begin{array}{c}0.006 \\
(0.027)\end{array}$ \\
\hline Age & & $\begin{array}{l}0.006 \\
(0.026)\end{array}$ & $\begin{array}{l}-0.035 \\
(0.051)\end{array}$ \\
\hline Access to credit & & $\begin{array}{l}0.602 \\
(0.432)\end{array}$ & $\begin{array}{l}-0.333 \\
(0.418)\end{array}$ \\
\hline Access to off-farm income & & $\begin{array}{c}-0.003 \\
(0.025)\end{array}$ & $\begin{array}{c}0.056 \\
(0.491)\end{array}$ \\
\hline Drought shock & & $\begin{array}{l}-0.038 \\
(0.054)\end{array}$ & $\begin{array}{l}-0.331 \\
(0.514)\end{array}$ \\
\hline Membership to cooperatives & & $\begin{array}{l}1.583 * * * \\
(0.584)\end{array}$ & $\begin{array}{l}-1.050 * \\
(0.567)\end{array}$ \\
\hline Membership to credit and saving group & & $\begin{array}{c}-0.038 \\
(0.054)\end{array}$ & $\begin{array}{l}-0.331 \\
(0.514)\end{array}$ \\
\hline Access to extension services & & $\begin{array}{c}0.637 \\
(0.590)\end{array}$ & $\begin{array}{c}0.024 \\
(0.405)\end{array}$ \\
\hline Access to climate information & & $\begin{array}{l}3.700^{*} \\
(2.11)\end{array}$ & $\begin{array}{c}0.006 \\
(0.026)\end{array}$ \\
\hline Risk aversion & & $\begin{array}{l}-0.045 \\
(0.424)\end{array}$ & $\begin{array}{c}0.006 \\
(0.027)\end{array}$ \\
\hline Access to land resources & & $\begin{array}{l}-0.333 \\
(0.418)\end{array}$ & $\begin{array}{c}-0.038 \\
(0.054)\end{array}$ \\
\hline Access to training & & $\begin{array}{c}-0.052 \\
(0.405)\end{array}$ & $\begin{array}{l}-0.151 \\
(0.451)\end{array}$ \\
\hline F-test & $7.54 * * *$ & $4.2 * * *$ & $4.9 * * *$ \\
\hline $\mathrm{R}^{2}$ & 0.061 & 0.032 & 0.27 \\
\hline No of observation & 3,321 & 3,321 & 3,321 \\
\hline
\end{tabular}


Standard errors are reported in parentheses, $* * *=$ significant at $1 \%, * *=$ significant at $5 \%$, $*=$ significant at $10 \%$. State level fixed effects included.

TABLE 7: Impact of Adoption of Biofortified Cassava on Farmers Income

\begin{tabular}{|c|c|c|c|}
\hline & No control & With control & With IV \\
\hline Biofortified cassava & $\begin{array}{l}2.16 * * * \\
(0.720)\end{array}$ & $\begin{array}{l}2.211 * * * \\
(0.614)\end{array}$ & $\begin{array}{l}1.825 * * * \\
(0.707)\end{array}$ \\
\hline Gender & & $\begin{array}{l}0.027 * * \\
(0.011)\end{array}$ & $\begin{array}{l}0.094 * * * \\
(0.019)\end{array}$ \\
\hline Land category & & $\begin{array}{c}0.012 \\
(0.007)\end{array}$ & $\begin{array}{l}0.001 \\
(0.006)\end{array}$ \\
\hline Adopters* Gender & & $\begin{array}{l}0.020 * * \\
(0.151)\end{array}$ & $\begin{array}{l}0.033 * * * \\
(0.080)\end{array}$ \\
\hline Adopters* Land category & & $\begin{array}{l}0.224 * * \\
(0.187)\end{array}$ & $\begin{array}{c}0.006^{*} \\
(0.004)\end{array}$ \\
\hline Education & & $\begin{array}{l}0.026^{* * *} * \\
(0.008)\end{array}$ & $\begin{array}{l}0.094 * * * \\
(0.019)\end{array}$ \\
\hline Household size & & $\begin{array}{l}0.227 * \\
(0.133)\end{array}$ & $\begin{array}{l}0.393 * * * \\
(0.088)\end{array}$ \\
\hline Marital status & & $\begin{array}{l}0.695 * * * \\
(0.183)\end{array}$ & $\begin{array}{c}0.010 \\
(0.007)\end{array}$ \\
\hline Years of Experience & & $\begin{array}{l}0.248 * * \\
(0.112)\end{array}$ & $\begin{array}{c}0.311 \\
(0.186)\end{array}$ \\
\hline Age & & $\begin{array}{c}0.009 \\
(0.009)\end{array}$ & $\begin{array}{l}0.020 \\
(0.118)\end{array}$ \\
\hline Access to credit & & $\begin{array}{l}-0.046 \\
(0.120)\end{array}$ & $\begin{array}{l}0.018 \\
(0.141)\end{array}$ \\
\hline Access to off-farm income & & $\begin{array}{l}1.268 * * * \\
(0.457)\end{array}$ & $\begin{array}{l}0.217 * * * \\
(0.035)\end{array}$ \\
\hline Drought shock & & $\begin{array}{l}0.048 * * * \\
(0.012)\end{array}$ & $\begin{array}{c}0.416 \\
(0.114)\end{array}$ \\
\hline Membership to cooperatives & & $\begin{array}{l}0.248^{*} \\
(0.136)\end{array}$ & $\begin{array}{l}-0.065^{* * * *} \\
(0.017)\end{array}$ \\
\hline Membership to credit and saving group & & $\begin{array}{l}-0.257 * * \\
(0.120)\end{array}$ & $\begin{array}{l}0.129 \\
(0.087)\end{array}$ \\
\hline Access to extension services & & $\begin{array}{l}0.869 * * * \\
(0.218)\end{array}$ & $\begin{array}{l}3.365 * * * \\
(0.653)\end{array}$ \\
\hline Access to climate information & & $\begin{array}{l}0.145^{* * * *} \\
(0.023)\end{array}$ & $\begin{array}{l}-0.025 \\
(0.018)\end{array}$ \\
\hline Risk aversion & & $\begin{array}{c}0.015 \\
(0.023)\end{array}$ & $\begin{array}{l}-0.048 \\
(0.037)\end{array}$ \\
\hline Access to land resources & & $\begin{array}{c}0.402 \\
(0.407)\end{array}$ & $\begin{array}{l}-0.073 \\
(0.461)\end{array}$ \\
\hline Access to training & & $\begin{array}{l}-0.008 \\
(0.019)\end{array}$ & $\begin{array}{c}0.015 \\
(0.022)\end{array}$ \\
\hline F-test & $6.37 * * *$ & $3.21 * * *$ & $7.42 * *$ \\
\hline $\mathrm{R}^{2}$ & 0.043 & 0.052 & 0.536 \\
\hline No of observation & 3,321 & 3,321 & 3,321 \\
\hline
\end{tabular}

Standard errors are reported in parentheses, $* * *=$ significant at $1 \%, * *=$ significant at $5 \%$,

$*=$ significant at $10 \%$. State level fixed effects included 


\section{Impact of adoption of biofortified cassava on welfare outcome indicators}

The results of the welfare impacts of adoption of biofortified cassava is presented in Table 8 and 9. As indicated in the methodology section, per-capita total expenditure, food expenditure and poverty headcount ratio were used as indicator for welfare. In these analysis, food expenditure and total expenditure were measured on per capita basis which was estimated using a log-linear functional form. The results of the per-capita total expenditure and per-capita food expenditure were reported in Table 8 and 9 respectively. Just as previous section, parsimonious specifications was done in which we estimated impacts without controls, with controls, and with IV. For this section, discussion is based on the computed IV results presented in Table 8 and 9. The result show that adoption of biofortified cassava has a positive and significant impact on per-capita total expenditure and per-capita food expenditure respectively. The direction of the estimated effect size shows a large improvement in the welfare outcomes of the farmers as a result of adoption of biofortified cassava. From Table 8, per-capita total expenditure increased by $39.1 \%$. In addition, per-capita food expenditure increased by $29.7 \%$. These results are in agreement with previous studies on adoption impacts of improved technology in Nigeria. For instance, Afolami et al. (2015) found that adopters of improved cassava technology have a better welfare status than non-adopters as it was found that adoption of improved cassava technology increased per capita consumption expenditure per annum and annual household income and subsequently contributed to overall poverty reduction among the adopters of the improved cassava technology. Like the previous specification, interaction term between the adoption of biofortified cassava and gender and farm size was included. We found a significant impact for both per-capita total expenditure and food expenditure. The third welfare indicator, that is, headcount poverty ratio, is a binary variable. However, the estimates for biofortified cassava will only represent changes in the probability of poverty instead of actual poverty reduction rates. Estimating the impact of adoption of biofortified cassava on poverty reduction instead of changes in the probability of poverty reduction will requires examining the distribution of observed poverty of adopters of biofortified cassava and the distribution of the counterfactual poverty of adopters of biofortified cassava had they not adopted biofortified cassava. In essence, we are to examine the poverty reduction impacts of the $39.1 \%$ per-capita total expenditure reported in Table 8 and also ascertain whether such changes are sufficient to lift the poor smallholder farmers above the poverty line. In doing so, we then, calculated changes in the headcount poverty ratio of the adopters of biofortified cassava as a result of the $39.1 \%$ increase in per-capita consumption expenditure. From the computed result, headcount poverty ratio has decreased by $21.3 \%$ points as a result of adoption of biofortified cassava. 
TABLE 8: Impact of Adoption of Biofortified Cassava on Per-capita total expenditure

\begin{tabular}{|c|c|c|c|}
\hline & No control & With control & With IV \\
\hline Biofortified cassava & $\begin{array}{l}0.46^{* * * *} \\
(0.143)\end{array}$ & $\begin{array}{l}0.415 * * * \\
(0.157)\end{array}$ & $\begin{array}{l}0.391 * * * * \\
(0.061)\end{array}$ \\
\hline Gender & & $\begin{array}{l}0.016^{* * * *} \\
(0.005)\end{array}$ & $\begin{array}{l}0.010^{*} \\
(0.006)\end{array}$ \\
\hline Land category & & $\begin{array}{l}0.388^{* * * *} \\
(0.116)\end{array}$ & $\begin{array}{c}0.003 \\
(0.004)\end{array}$ \\
\hline Adopters* Gender & & $\begin{array}{l}0.131 * \\
(0.069)\end{array}$ & $\begin{array}{l}0.207 * \\
(0.121)\end{array}$ \\
\hline Adopters* Land category & & $\begin{array}{l}0.127 \\
(0.127)\end{array}$ & $\begin{array}{c}0.002 \\
(0.007)\end{array}$ \\
\hline Education & & $\begin{array}{l}0.243 * * \\
(0.112)\end{array}$ & $\begin{array}{c}0.017 \\
(0.109)\end{array}$ \\
\hline Household size & & $\begin{array}{l}0.030 * * * \\
(0.008)\end{array}$ & $\begin{array}{r}0.226 \\
(0.157)\end{array}$ \\
\hline Marital status & & $\begin{array}{l}-0.055 \\
(0.097)\end{array}$ & $\begin{array}{c}0.011 \\
(0.128)\end{array}$ \\
\hline Years of Experience & & $\begin{array}{l}0.334 \\
(0.331)\end{array}$ & $\begin{array}{c}0.175 \\
(0.027)\end{array}$ \\
\hline Age & & $\begin{array}{l}0.003 \\
(0.004)\end{array}$ & $\begin{array}{c}0.009 \\
(0.007)\end{array}$ \\
\hline Access to credit & & $\begin{array}{l}-0.022 \\
(0.016)\end{array}$ & $\begin{array}{l}-0.218 \\
(0.159)\end{array}$ \\
\hline Access to off-farm income & & $\begin{array}{l}0.207^{*} \\
(0.121)\end{array}$ & $\begin{array}{r}0.059 \\
(0.164)\end{array}$ \\
\hline Drought shock & & $\begin{array}{l}0.122 \\
(0.169)\end{array}$ & $\begin{array}{r}-0.024^{*} \\
(0.012)\end{array}$ \\
\hline Membership to cooperatives & & $\begin{array}{l}0.122 \\
(0.169)\end{array}$ & $\begin{array}{l}-0.055 \\
(0.125)\end{array}$ \\
\hline Membership to credit and saving group & & $\begin{array}{l}-0.104 \\
(0.155)\end{array}$ & $\begin{array}{l}-0.075 \\
(0.112)\end{array}$ \\
\hline Access to extension services & & $\begin{array}{l}0.413 * * \\
(0.194)\end{array}$ & $\begin{array}{l}1.796^{*} \\
(1.104)\end{array}$ \\
\hline Access to climate information & & $\begin{array}{l}0.228 * * * \\
(0.039)\end{array}$ & $\begin{array}{l}-0.094 \\
(0.035)\end{array}$ \\
\hline Risk aversion & & $\begin{array}{l}0.074 * * \\
(0.037)\end{array}$ & $\begin{array}{l}0.102 * \\
(0.059)\end{array}$ \\
\hline Access to land resources & & $\begin{array}{l}0.016 \\
(0.023)\end{array}$ & $\begin{array}{l}0.040 \\
(0.029)\end{array}$ \\
\hline Access to training & & $\begin{array}{c}-0.011 \\
(0.053)\end{array}$ & $\begin{array}{l}0.074 * * \\
(0.037)\end{array}$ \\
\hline F-test & $5.3 * * *$ & $3.2 * * *$ & $4.1 * * *$ \\
\hline $\mathrm{R}^{2}$ & 0.034 & 0.53 & 0.65 \\
\hline No of observation & 3,321 & 3,321 & 3,321 \\
\hline
\end{tabular}

Standard errors are reported in parentheses, $* * *=$ significant at $1 \%$, **= significant at $5 \%$, $*=$ significant at $10 \%$. State level fixed effects included. Per-capita total expenditure are measured in per capita and also transformed in logarithm. 
TABLE 9: Impact of Adoption of Biofortified Cassava on Per-capita food expenditure No control With control With IV

Biofortified cassava

Gender

Land category

Adopters* Gender

Adopters* Land category

Education

Household size

Marital status

Years of Experience

Age

Access to credit

Access to off-farm income

Drought shock

Membership to cooperatives

Membership to credit and saving group

Access to extension services

Access to climate information

Risk aversion

Access to land resources

Access to training

F-test

$\mathrm{R}^{2}$

No of observation

$0.57 * * *$
$(0.091)$

$0.542 * * *$

(0.100)

$-1.185^{* *}$

(0.558)

0.092

(0.480)

$1.066^{*}$

(0.594)

$-0.028 * *$

$(0.036)$

0.042

(0.039)

-1.060 *

(0.618)

3.076*

(1.800)

$1.066^{*}$

$(0.594)$

$-1.185^{* *}$

(0.558)

0.029

(0.062)

$-2.157 * *$

(0.867)

$-0.003$

(0.005)

$-0.002$

(0.003)

0.010

(0.008)

$-0.166$

(0.102)

$-0.005$

(0.007)

$-0.294 * *$

(0.140)

0.156

(0.117)

0.005

$(0.008)$

$4.3 * * *$

$6.4 * * *$

0.046

0.026

3,321

3,321
$0.297 * * *$

(0.036)

$1.408 * *$

(0.615)

$-0.606$

(0.557)

$0.003 * *$

(0.518)

$0.986 * * *$

(0.703)

$-1.326$

(0.776)

$2.705^{* * * *}$

(0.838)

$-0.507$

(0.497)

$-0.030$

(0.032)

$1.408 * *$

(0.615)

1.392*

(0.748)

$-0.961$

(2.256)

0.001

(0.007)

$-0.003$

(0.004)

$-0.014$

(0.126)

$0.275^{*}$

(0.146)

0.154

(0.134)

0.001

(0.009)

$-0.023$

(0.099)

$-0.312 * * *$

(0.098)

$7.1 * * *$

0.062

3,321

Standard errors are reported in parentheses, $* * *=$ significant at $1 \%, * *=$ significant at $5 \%$,

$*=$ significant at $10 \%$. State level fixed effects included. Per-capita total expenditure are measured in per capita and also transformed in logarithm. 


\section{CONCLUSIONS}

Improving the welfare and productivity of smallholder farmers through the adoption of improved agricultural technology is of paramount priority in Nigeria in order to lift these farmers from poverty and ensure that they are food secured. However, adoption of such technology such as biofortified cassava is low in SSA and in particular in Nigeria. With the intents of improving the productivity and welfare of farmers, biofortified staple food crops including biofortified cassava was bred in 2011. Using a household-level data from smallholder farmers in Nigeria, the study examined the welfare and productivity impact of adoption of biofortified cassava in Nigeria. The study examined to what extent, adoption of biofortified cassava had improved the farm yield and farmers income and also their welfare outcomes. Instrumental variable regression was in the study to control for endogeneity of adoption of biofortified cassava. The empirical findings of the study include the fact that smallholder farmers who adopted the biofortified cassava increased their farm yield by $28.5 \%$. Also, farmers income increased by $\$ 22,812$ as a result of adoption of biofortified cassava. These results prove that adoption of biofortified cassava enabled the farmers to improve their income and productivity which justify the reasons why more farmers should adopt the different varieties of biofortified cassava. Regarding the welfare outcomes, the results of the study showed a positive and significant impact on per-capita total and food consumption expenditure with the size of the impact suggesting an improvement in welfare as a result of adoption of biofortified cassava. In particular, adoption of biofortified cassava increased the per-capita total expenditure of the smallholder farmers by $39.1 \%$ and subsequently decease poverty head count ratio by $21.3 \%$ points. This further established the fact that adoption of biofortified cassava among the smallholder farmers has improved the welfare of the farmers there by declining their poverty status. In addition, the impact of the interaction term between adoption of biofortified cassava and gender as well as farm size is statistically significant indicating the presence of heterogeneity impact based on gender and farm size. This implies that adoption of biofortified cassava had benefitted more the male gender. Therefore, in order to ensure equal benefits among the two genders, the female headed household should be massively mobilized to adopt the biofortified cassava so as to improve their productivity, income 
and welfare outcomes. Also, more high yielding varieties of biofortified cassava should be breed and circulated so that cassava farmers can further increase their productivity and income.

\section{ACKNOWLEDGEMENTS}

The authors will like to appreciate the efforts of cassava farmers association and ADPs for their immense contribution towards the success of this research.

\section{CONFLICT OF INTERESTS}

Authors have declared that no competing interests exist.

\section{FUNDING INFORMATION}

This research does not receive any external funding.

\section{REFERENCES}

Afolami, C. A., Obayelu, A. E and Vaughan, I. I. (2015). Welfare impact of adoption of improved cassava varieties by rural households in South Western Nigeria. Agriculture and Food Economics, 3, 18-34.

Chibwana, C., Fisher, M., \& Shively, G. (2012). Cropland allocation effects of agricultural input subsidies in Malawi. World Development, 40(1), 124-133.

FAO, 2013, Food and Agriculture Organization (FAO) website. www.fao.org.

Foster, J., Greer, J., \& Thorbecke, E. (1984). A class of decomposable poverty measures. Econometrica, 52(3), 761-765.

Imbens, G. W., \& Wooldridge, J. W. (2009). Recent developments in the econometrics of program development. Journal of Economic Literature, 47(1), 5-86.

National Bureau of Statistics Nigeria (NBSN) (2010). Nigeria poverty profile 2010. Available onlineat:http://www.nigerianstat.gov.ng/pdfuploads/Nigeria\%20Poverty\%20Profile\%202 010.pdf.

Nestel, P., Bouis, H. E., Meenakshi, J., and Pfeiff er, W. (2006). Biofortification of staple food crops. The Journal of nutrition, 136(4):1064-1067.

Otekunrin, O.A and Sawicka, B. (2019). "Cassava, a $21^{\text {st }}$ century staple crop: How can Nigeria harness its Enormous Trade potentials?” Acta Scientific Agriculture 3(8), 194-202.

Oparinde, A., Abhijit, B., Ekin, B. and Ilona, P. (2016). Information and consumer willingness to pay for biofortified yellow cassava: evidence from experimental auctions in Nigeria. Agricultural Economics, 47,215-233.

Phillips T. P., Taylor D. S., Sanni L. \& Akoroda, M.O., (2004). A cassava industrial revolution in Nigeria: The Potential for a new industrial crop". International Institute of Tropical Agriculture, Ibadan, Nigeria". International Fund for Agricultural Development, Food and Agriculture Organization of the United Nations, Rome, Italy. 
Rice, A. L., West Jr, K. P., and Black, R. E. (2004). Vitamin a deficiency. Comparative quantification of health risks: global and regional burden of disease attributes to selected major risk factors. Geneva: World Health Organization, pages 11-56.

Ricker-Gilbert, J., Jayne, T. S., \& Chirwa, E. (2011). Subsidies and crowding out: A double hurdle model of fertilizer demand in Malawi. American Journal of Agricultural Economics, 93(1), 26-42.

Ricker-Gilbert, J., Mason, N. M., Darko, F. A., \& Tembo, S. T. (2013). What are the effects of input subsidy programs on maize prices? Evidence from Malawi and Zambia. Agricultural Economics, 44(6), 671-686.

Robins, J. M., \& Rotnitzky, A. (1995). Semiparametric efficiency in multivariate regression models with missing data. Journal of the American Statistical Association, 90(429), 122129.

Robins, J., Sued, M., Lei-Gomez, Q., \& Rotnitzky, A. (2007). Comment: Performance of double robust estimators when " inverse probability" weights are highly variable. Statistical Science, 544-559.

Saltzman, A., Birol, E., Bouis, H. E., Boy, E., De Moura, F. F., Islam, Y. Pfeiffer, W. H. (2014). Biofortification: Progress towards a more nourishing future. Bread and Brain, Education and Poverty. Pontifical Academy of Sciences, Vatican City. Scripta varia 125. Retrieved from: www.pas. va/content/dam/accademia/pdf/sv125/sv125-bouis.pdf

Shively, G., Chibwana, C., Fisher, M., Jumbe, C., Masters, W. (2012). Measuring impacts of Malawi's farm input subsidy program. Paper presented at the International Conference of Agricultural Economists. Foz du Iguacu Brazil, 20 August 2012.

Wooldridge, J. M. (2007). Inverse probability weighted estimation for general missing data problems. Journal of Econometrics, 141(2), 1281-1301.

Wooldridge, J. M. (2010). Econometric analysis of cross section and panel data. The MIT Press. 